\title{
Factors Associated to Non-Attendance to Dental Care among Adolescents-Suggesting a Model
}

\section{—Analysis of "Life \& Health-Young People" a Cross-Sectional Public Health Survey among Adolescents in Örebro County, Sweden}

\author{
Annika Gustafsson1,2*, Carina Persson³ ${ }^{3}$ Carina Källestål4 \\ ${ }^{1}$ Department of Pedodontics, Postgraduate Dental Education Center, Örebro County Council, Örebro, Sweden \\ ${ }^{2}$ Department of Dental Research, Public Dental Service, Region Örebro County, Faculty of Medicine and Health, Örebro \\ University, Örebro, Sweden \\ ${ }^{3}$ Department for Sustainable Development, Region Örebro County, Faculty of Medicine and Health, Örebro University, Örebro, \\ Sweden \\ ${ }^{4}$ Department of Women's and Children's Health, Uppsala University, Uppsala, Sweden \\ Email: ^Annika.Gustafsson@regionorebrolan.se, Carina.Persson@regionorebrolan.se, Carina.Kallestal@kbh.uu.se
}

How to cite this paper: Gustafsson, A., Persson, C., \& Källestål, C. (2018). Factors Associated to Non-Attendance to Dental Care among Adolescents-Suggesting a Model. Psychology, 9, 2731-2751. https://doi.org/10.4236/psych.2018.913157

Received: October 30, 2018

Accepted: December 4, 2018

Published: December 7, 2018

Copyright (c) 2018 by authors and Scientific Research Publishing Inc. This work is licensed under the Creative Commons Attribution International License (CC BY 4.0).

http://creativecommons.org/licenses/by/4.0/

cc) (i) Open Access

\begin{abstract}
Background: Understanding why adolescents miss dental appointments is central to promoting people's oral health into adulthood. Studies on non-attendant adolescents are rare. Method: Using information from a population-based survey of schoolchildren in Örebro County, Sweden, we aimed to find factors associated with adolescents' dental non-attendance and to suggest a risk-factor model for non-attendance. The 2014 survey of all pupils in three grades ( ages 13,15 , and 17$)$ in the county $(\mathrm{N}=7399)$ had a response rate of $80 \%$. The questionnaire asked 67 or 86 questions (depending on grade) on five components: socioeconomic conditions, quality of life, social relations, lifestyle and health (with two specific questions on dental care and oral health), social cohesion and social capital. Using a model based on risk factors identified in the literature, we used descriptive statistics, bivariate analyses, and logistic regressions to find associations between dental attendance and potential risk factors. Results: Youth were non-attendant $(\mathrm{n}=171)$ and attendant $(\mathrm{n}=$ 4236). Strong associations were found between non-attendance being a boy, being born outside Sweden, and living with parents not in the labor market. Health and health behaviors such as consuming sweet drinks or foods every day and being overweight were also associated with non-attendance. A model for risk of non-attendance based on variables significant in the analysis is presented. Conclusions: This study shows a strong association between non-attendant behavior and sociodemographic factors and health behavior. It also adds knowledge of the increased vulnerability to non-attendance in ado-
\end{abstract}


lescents having at least one disability and/or experience of critical life.

\section{Keywords}

Adolescence, Dental Attendance, Health Behaviors, Population

Characteristic, Psychosocial Concomitants, Self-Rated Oral Health

\section{Introduction}

Non-attendance at scheduled appointments is a well-recognized problem in health (Chariatte, Berchtold, Akre, Michaud, \& Suris, 2008; Neal, Hussain-Gambles, Allgar, Lawlor, \& Dempsey, 2005; Waller \& Hodgkin, 2000) dental care (Haugejorden, Klock, Astrom, Skaret, \& Trovik, 2008; Skaret, Berg, Kvale, \& Raadal, 2007; Skaret, Raadal, Berg, \& Kvale, 1999; Skaret, Raadal, Kvale, \& Berg, 1998, 2000; Wogelius, Poulsen, \& Sorensen, 2003). Studies from the United States, Latin America, and Europe estimate non-attendance from 6.5\% to 30\% (Giunta et al., 2013; Neal et al., 2001; Waller \& Hodgkin, 2000). Missed appointments may put the patient's own health and treatment at serious risk (Appleton, Powell, \& Coombes, 2016; Neal et al., 2005; Waller \& Hodgkin, 2000) and are extremely cost-inefficient for health care (Kheirkhah, Feng, Travis, Tavakoli-Tabasi, \& Sharafkhaneh, 2016; Thomas, 2004).

Non-attending children risk unnecessary negative health outcomes when necessary examinations or treatments are not conducted (Andrews, Morgan, Addy, \& McNeish, 1990). Children have a fundamental right to health and dental care to attain and retain their best health and well-being (Pais \& Bissell, 2006) and they do not themselves choose to miss scheduled appointments. Rather, they are not brought by their caregivers (Roe, Appleton, \& Powell, 2015). Earlier studies have reported that pediatric outpatient non-attendance is more likely in lower socioeconomic groups (McClure, Newell, \& Edwards, 1996) and in families with social problems (Cooper \& Lynch, 1979). Longer waiting times (Bowman, Bennett, Houston, Aitchison, \& Dutton, 1996) and receiving the appointment by post rather than in person (McClure et al., 1996) increase missed appointments. Cameron et al. concluded that parental motivation and practical and social barriers should be considered when meeting families with a history of non-attendance (Cameron et al., 2014).

In the Nordic countries, all children and adolescents have free access to dental care, regardless family socioeconomic or insurance status, but not all Nordic countries cover orthodontic treatment (Socialstyrelsen, 2015a). Despite this, a study reported that $16.4 \%$ of adolescent patients have missed or cancelled $20 \%$ or more of their public dental care appointments (Skaret et al., 1999). A similar pattern was found in specialized pediatric care (Gustafsson, Broberg, Bodin, Berggren, \& Arnrup, 2010), where $11 \%$ of scheduled dental appointments were either missed or cancelled by children and adolescents referred for dental beha- 
vior management problems.

Several reasons have been suggested for non-attendance. Figure 1 shows a modified conceptual model of self-rated psychosocial and sociodemographic concomitants to non-attendance based on Carpiano's model of neighborhood social capital processes on individual health (Carpiano, 2007) and summarizes the factors associated in the literature with attendance to dental care as described below.

\subsection{Sociodemographic Factors}

Component 1 consists of gender, school grade (approximate age), ethnicity, and parental occupational status. Sociodemographic factors are reported to be strongly related to not attending scheduled dental appointments, which is more common among adolescents than young children (Davoglio, Abegg, \& Aerts, 2013; Skaret et al., 1998; Zimmer-Gembeck, Alexander, \& Nystrom, 1997), among boys than girls (Okullo, Astrom, \& Haugejorden, 2004; Ostberg, Ericsson, Wennstrom, \& Abrahamsson, 2010; Skaret et al., 2007; Skaret et al., 1999; Skaret et al., 1998), and in families with low parental socioeconomic status (Freire, Sheiham, \& Hardy, 2001; Gustafsson, Arnrup, Broberg, Bodin, \& Berggren, 2007; Lopez \& Baelum, 2007; Lu, Wong, Lo, \& McGrath, 2011; Okullo et al., 2004; Ostberg et al., 2010; Yu, Bellamy, Schwalberg, \& Drum, 2001).

\subsection{Self-Rated Health}

General health, disabilities, and oral health are included in Component 2, self-rated health. Non-attendant behavior is more common among those with bad oral health than in those with good oral health (Lopez, 2007; Ridell, Matsson,

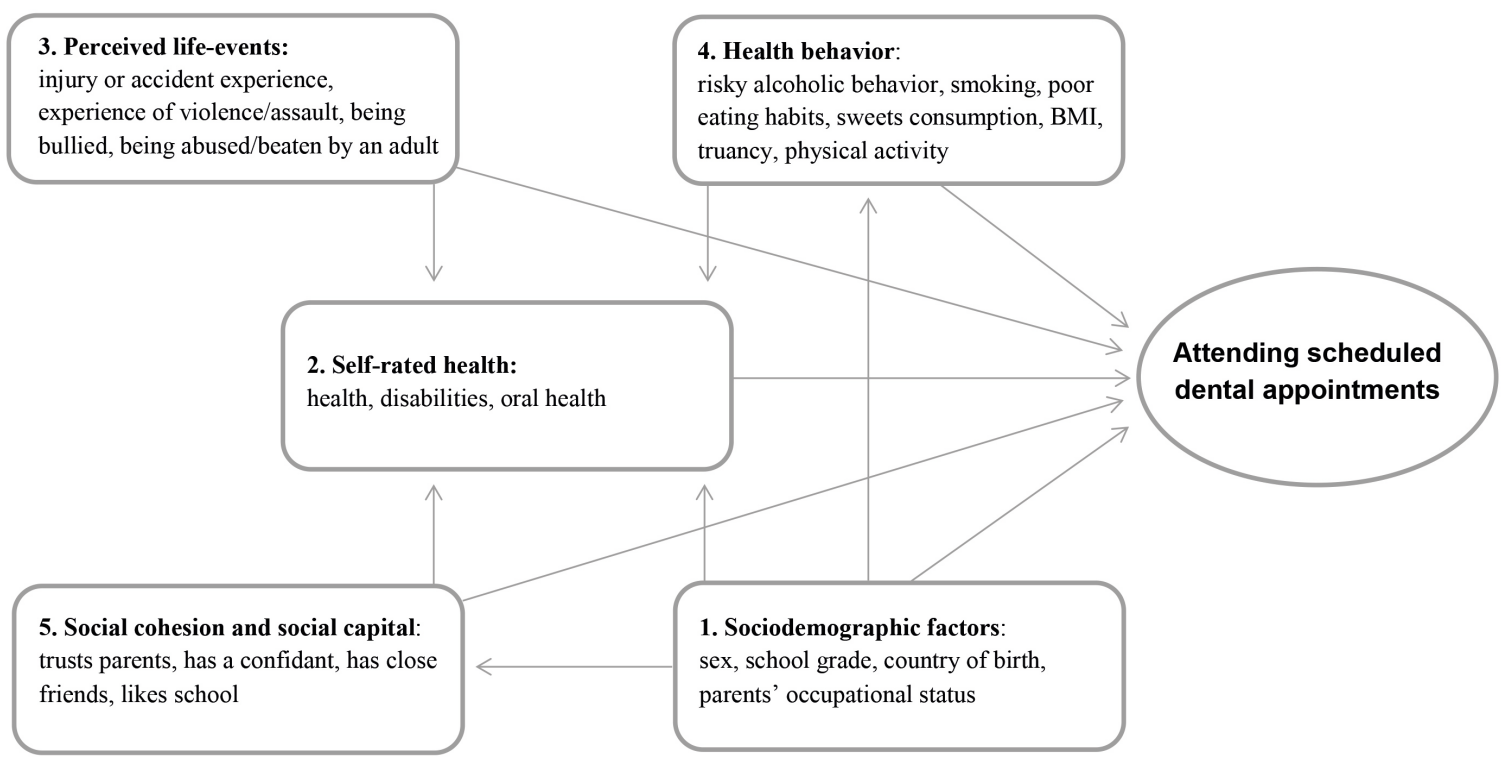

Figure 1. Conceptual model of attending scheduled dental appointments, adapted from Carpiano's model (Carpiano, 2007) of factors' reported associations with attendance at dental care appointments. The box numbers refer to the components described in the text. 
\& Mejare, 2007; Vingilis, Wade, \& Seeley, 2007). The connection between general health, disabilities, and oral health is well-known (Blomqvist, Holmberg, Fernell, Ek, \& Dahllof, 2006; Brogardh-Roth et al., 2017; Carlsson, Hakeberg, Blomkvist, \& Wide Boman, 2013). Oral health problems, such as poor oral hygiene, and gingival health has been noted in adolescents with poor general health and/or disabilities.

\subsection{Perceived Life Events}

Component 3 in the model includes accidents/injuries, experience of violence/assault, having been bullied, and having been abused/beaten by an adult. Critical life events-often unwanted, uncontrolled, and sometimes life-threatening situations-are included in this category. Such life events have a negative influence on both mental (Brown \& Harris, 1978) and self-rated overall health (Denton, Prus, \& Walters, 2004) and non-attendant behavior (Kvist, Annerback, Sahlqvist, Flodmark, \& Dahllof, 2013).

\subsection{Health Behavior}

Alcohol, smoking, and dietary habits including sugar consumption, physical activity, body mass index (BMI), and school attendance are included in Component 4. High alcohol consumption and smoking are well-known health risks (NCD Risk Factor Collaboration (NCD-RisC), 2017; Neovius, 2011), and health and physical activity, sugar consumptions, eating habits, and general and oral health have been shown to be strongly related (NCD Risk Factor Collaboration (NCD-RisC), 2017). There is also a link between physical inactivity and dental behavior management problems (DBMP) (Gustafsson et al., 2007).

\subsection{Social Cohesion and Social Capital}

Component 5 in the model describes the availability of social support, such as trusted parents, a close relationship with a confidant, and friends and happiness at school. Social interaction problems are more common among children and adolescents with DBMP than with children and adolescents without (Gustafsson et al., 2007). Among those referred for DBMP, unstable family situations and parents with psychological problems (e.g., high levels of dental fear and depressed mood), predict avoidance behavior (Gustafsson et al., 2007; Gustafsson et al., 2010). Skaret et al. also reported that teenagers who had left school were more likely to miss dental appointments and were at increased risk for future dropout from dental care (Skaret et al., 1999).

Avoidance may be the most extreme of DBMP, varying from irregular dental attendance to dropping out entirely from dental treatment. Children and adolescents with frequently missed or cancelled appointments are extremely difficult to contact and therefore constitute a group that is difficult to study (Hallberg, Camling, Zickert, Robertson, \& Berggren, 2008; Skaret et al., 1999; Skaret, Raadal, Kvale, \& Berg, 2003), this cross-sectional survey gave us an opportunity to identify non-attenders and factors associated with this behavior. Children and 
adolescents who avoid dental treatment present with high levels of caries and dental fear (Ridell et al., 2007). It seems logical to assume that non-attendance or infrequent attendance influences the outcome in patients with dental problems. When they attend treatment, they probably hope to alleviate their dental problems, but until treatment is successful, they may also have progressively greater fear. When this fear is expressed in non-attendance, the patient is at increased risk of entering a cycle of deteriorating dental health, more extreme treatments, poorer outcomes, higher levels of fear, more avoidance, poorer dental health, and so on. It is therefore important to foresee and prevent discontinuation of treatment. Research on the effect of psychosocial and sociodemographic factors on treatment discontinuity that focus on how to meet and treat these challenging patients is needed in order to give them the care they are entitled to.

The aims of this study were 1) by identifying the adolescents who reported that they sought dental care only for acute pain or not at all, estimate the prevalence of self-rated non-attendance to dental care, 2) to find factors associated with non-attendance among adolescents as sociodemographic factors, self-rated health, perceived life events, health behavior, social cohesion and social capital, and by using these identified risk-factors for non-attendance 3) suggest a risk factor model for non-attendant behavior.

\section{Methods}

\subsection{Study Population}

The cross-sectional survey, "Life \& Health: Youth" was conducted in Örebro County, Sweden, in April and May of 2014. The county then had a population of 286079 , with $23 \%$ (65 798) aged $\leq 19$ years. All pupils in the county $(\mathrm{N}=9279)$ in compulsory school years 7 ( $\sim 13 \mathrm{yrs})$ and $9(\sim 15 \mathrm{yrs})$ and high school Grade 2 ( $\sim 17$ yrs) were invited to participate. In Sweden, about $76 \%$ of adolescents attend high school. The pupils were asked through a self-administered anonymous questionnaire about their sociodemographic background, physical and mental health, lifestyle, and life experiences. The response rate was $80 \%(\mathrm{n}=7399)$ and non-respondents (1880) were mainly pupils absent from school because they were at work to obtain practical experience, ill, or for other unspecified reasons the day the questionnaires were distributed. All 4407 adolescents who answered the specific selected questions for this study were included in the present study (Figure 2).

\subsection{Data Collection}

Contact people in the schools (administrators and teachers) distributed and collected the questionnaires, which were completed and collected anonymously in classrooms.

\subsection{Measures}

The questionnaires included 67 items for those in compulsory year 7 and 86 for 


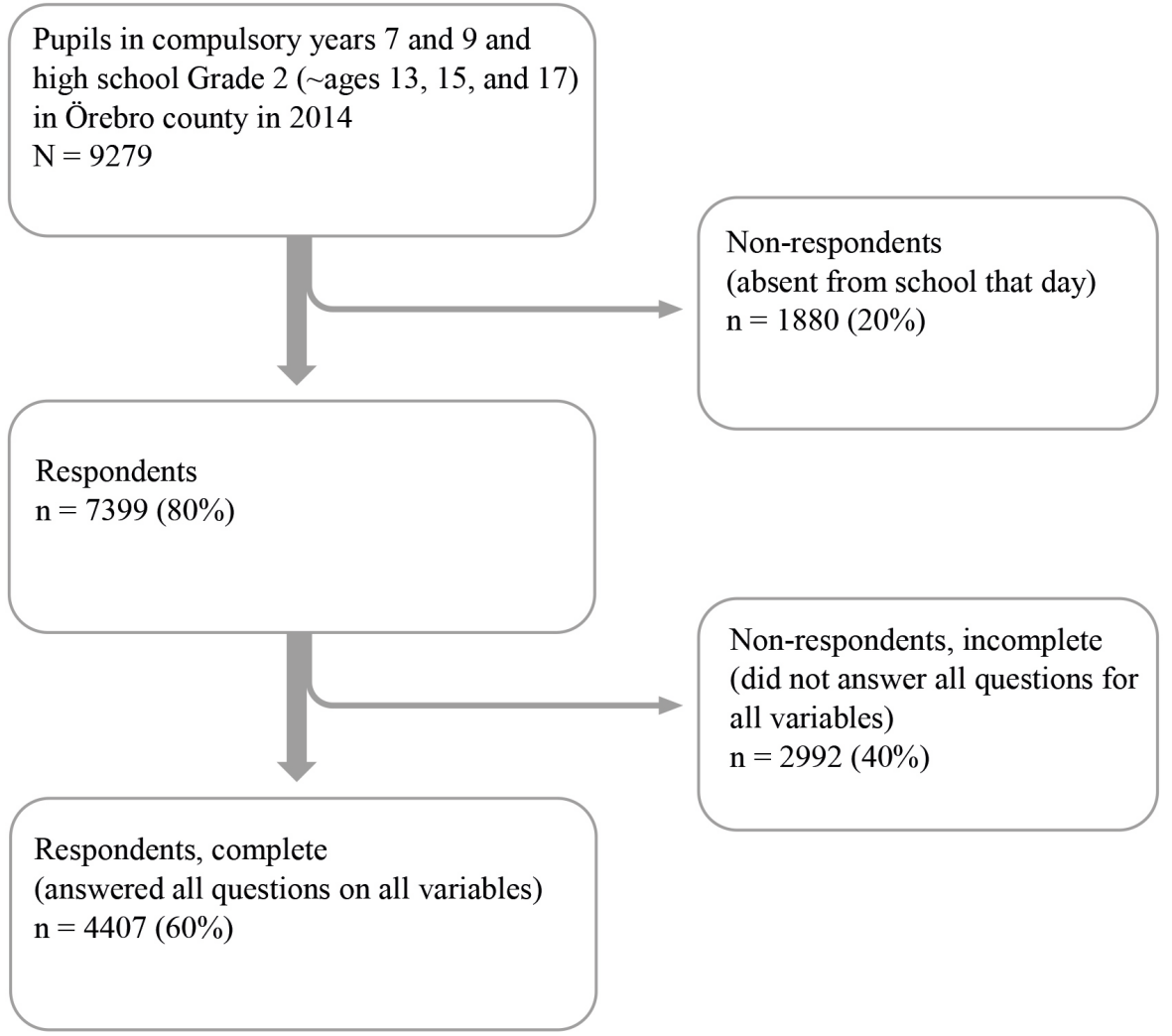

Figure 2. Flowchart of adolescents included in the "Life \& Health: Youth" survey, Örebro County, Sweden.

those in year 9 and Grade 2. There was one question about dental attendance and one about oral health that were identical for all three grades. The other questions were divided into areas such as socioeconomic conditions, family situation, medical and psychosocial history, daily life, psychosocial adjustment, and interactions with others.

\subsection{Dependent Variable}

Attending scheduled dental appointments was the dependent variable. The survey item: "How often do you go to the dentist/dental hygienist?" had 3 possible answers: 1) I go regularly to the dentist/dental hygienist, 2) I only go when it is absolutely necessary, as in an emergency or when I have a toothache, and 3) I completely avoid dental care. The answers were dichotomized, and adolescents who responded with (2) or (3) were designated as non-attendant.

\subsection{Independent Variables}

From the questionnaire's 61 or 86 items, we chose 24 independent variables based on the conceptual model shown in Figure 1. The variables were grouped into the following components 1) Sociodemographic factors, 2) Self-rated health, 3) Perceived lifeevents, 4) Health behavior, and 5) Social cohesion and social capital. See Table 1 for description of the variables. 
Table 1. Independent variables chosen from the "Life \& Health: Youth" survey, Örebro County, Sweden.

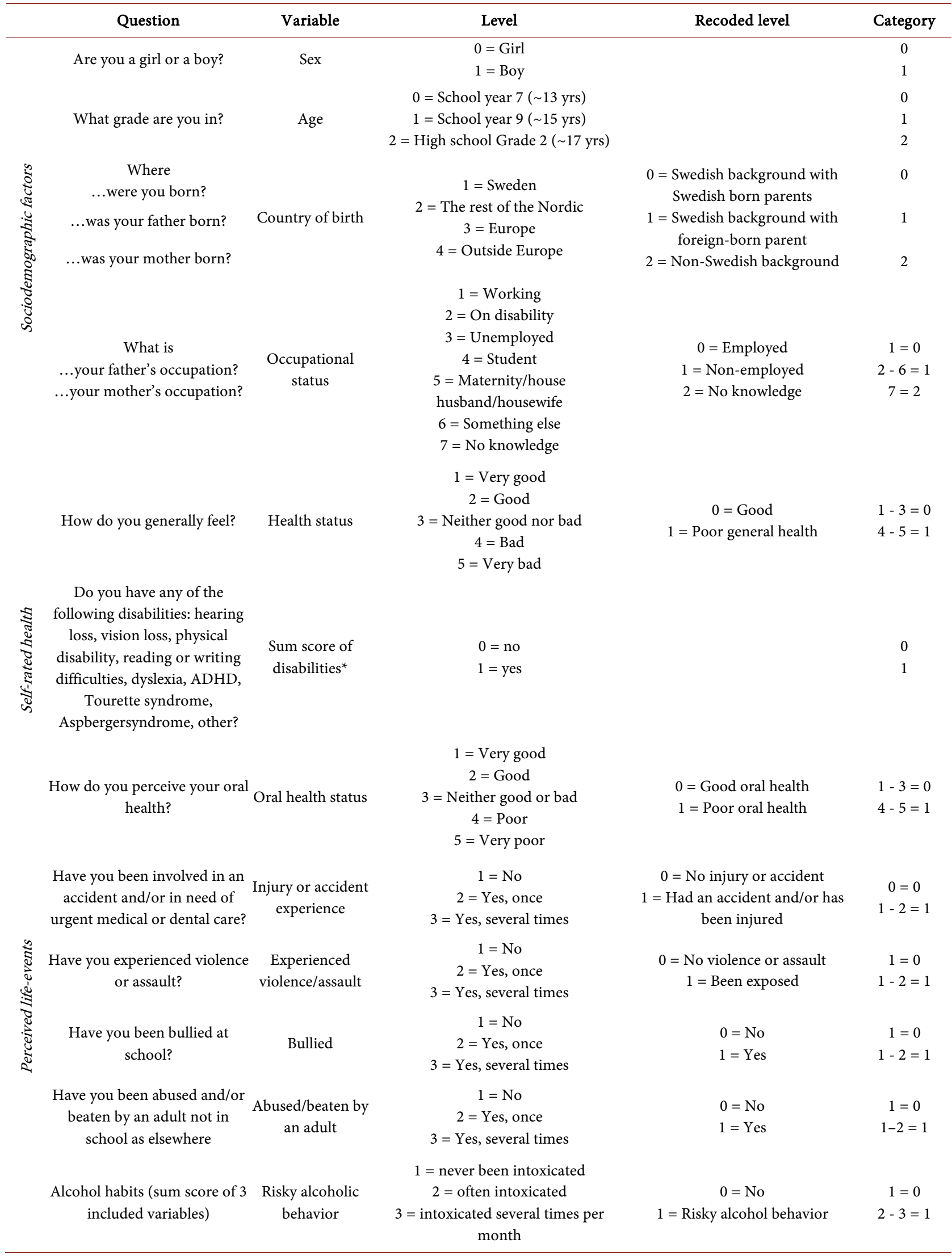




\section{Continued}

Do you smoke

How often do you eat breakfast, lunch, and dinner?

How often do you eat sweets/drink soda or juice

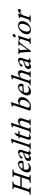

How often do you skip school Skipping school

How often do you exercise for

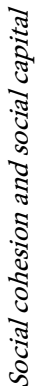
more than 30 minutes and hard enough to perspire?

I trust my parent/parents

How do you like school?

Physical activity

Parental trust

Do you have anyone with whom you can share your innermost feelings?

Has a confidant

I have close friends at school Has close friends

Likes school

$$
1=\text { No }
$$

$2=$ No, but I've tried

$3=$ No, I've quit

$4=$ Yes, sometimes

$$
5=\text { Yes, daily }
$$$$
1=\text { Every day }
$$

$2=4-6$ days per week

$3=1-3$ days per week

$4=$ Rarely or never

$1=$ Rarely or never

$2=$ Once per week

$3=\mathrm{A}$ few times a week

$$
4=\text { Everyday }
$$

$5=$ Several times per day

$1=$ Underweight $(<18.5 \mathrm{~kg})$

$2=$ Normal weight $(18.5-24.9 \mathrm{~kg})$

3 = Overweight $(25-29.9 \mathrm{~kg})$

$4=$ Obese $(>30 \mathrm{~kg})$

$$
1=\text { Never }
$$

$2=$ Yes, sometimes during the term

$3=$ Yes, once per month

$4=$ Yes, $2-3$ per month

$5=$ Yes, once a week

$6=$ Yes, several times per week

$$
\begin{gathered}
1=\text { everyday } \\
2=4-6 \text { times/week } \\
3=2-3 \text { times/week } \\
4=\text { once a week } \\
5=1-3 \text { times/month }
\end{gathered}
$$

$6=$ less than once/month

$$
7=\text { never }
$$

$1=$ Completely correct

$2=$ Mostly correct

$3=$ Neither correct nor incorrect

$4=$ Mostly incorrect

5 = Completely incorrect

$$
\begin{gathered}
1=\text { Yes, absolutely } \\
2=\text { Yes maybe } \\
3=\text { Probably not } \\
4=\text { No } \\
1=\text { Completely correct } \\
2=\text { Mostly correct }
\end{gathered}
$$

$3=$ Neither correct nor incorrect

$4=$ Mostly incorrect

5 = Completely incorrect

$$
1=\text { Very good }
$$$$
2=\text { Good }
$$

$3=$ Neither good or bad

$$
4=\mathrm{Bad}
$$

$5=$ Very bad

$$
0=\text { No }
$$

$1-3=0$

$1=$ Yes

$4-5=1$

$0=$ Regular eating habits

$1=$ Neither good nor bad eating habits

$2=$ Irregular eating habits

$1-2=0$

$3=1$

$4=2$

$0=$ Not often

$1-2=0$

$1=$ Consumes sweets and sweet

$3-5=1$ drinks every day

$$
\begin{array}{cc}
0=\text { No overweight } / \text { obese } & 1-2=0 \\
1=\text { Overweight } & 3=1 \\
2=\text { Obese } & 4=2
\end{array}
$$

$0=$ Less than 2 times per month $\quad 1-3=0$

$1=2$ times or more per month $\quad 4-6=1$

$0=$ regular physical activity $\quad 1-3=0$

$1=$ irregular physical activity $\quad 4-7=1$

$$
\begin{array}{ll}
0=\text { Yes } & 1-2=0 \\
1=\text { No } & 3-5=1
\end{array}
$$

$$
\begin{array}{ll}
0=\text { Yes } & 1-2=0 \\
1=\text { No } & 3-4=1
\end{array}
$$

$$
\begin{array}{ll}
0=\text { Yes } & 1-2=0 \\
1=\text { No } & 3-5=1
\end{array}
$$

${ }^{*}$ Self-rated disabilities 


\subsection{Statistical Methods}

Bivariate analyses between the dependent variable (attendance to dental care) and the various independent variables were conducted by binary logistic regression. To analyze the strength of each independent variable, while considering the relationships between the dependent and independent variables, we conducted multivariate analyses with binary logistic regression on the categorical data (stepwise forwards and backwards). Multicollinearity was accounted for through bivariate correlation matrices and the standard errors for the beta coefficients in the multivariate analysis. Significant variables in the bivariate analyses were entered in a sequence of multiple logistic regression analyses with group (non-attendant adolescents $=1$, attendant adolescents $=0$ ) as the dependent variable within each component ( $1-5$ in the conceptual model). The first model was conducted with only the individual socio-demographic factors followed by a new component for each model step. The analytic order thus started with individual factors and health risk factors that were strongly related to non-attendant adolescents. The following components that were introduced in the analysis were perceived life events, and health behavior. Finally, social cohesion and social capital were included in the analysis. Variables with non-significant oddsratios in the bivariate analysis or those with multicollinearity (i.e. general health, exposed to violence/assault, truancy, physical activity at least $60 \mathrm{~min} /$ day)were excluded. Nagelkerke's $R^{2}$ was calculated in each multiple logistic regression model. Nagelkerke's $\mathrm{R}^{2}$ is a pseudo $\mathrm{R}$ square that generalizes the coefficient of determination with values between 0 and 1 , where 0 denotes that the model does not explain any variation in the outcome variables and 1 that the model completely explains all variation.

The level of significance was set at $5 \%(p<0.05)$. All statistical analyses were performed using the Statistical Package for the Social Sciences (SPSS, version 22.0; SPSS, Chicago, IL, USA).

\subsection{Ethical Approval}

To ensure their confidentiality, the adolescents were provided sealable envelopes in which to leave their completed questionnaires. They were informed both orally and in writing about the purpose of the study and were told that all the information collected would be strictly confidential. The schools informed the parents of those in years 7 and 9. The parents of respondents in high school Grade 2 were not informed because in Sweden adolescents $>15$ have the right to make their own decisions in such matters. The study was approved by the regional Ethical Review Board of Uppsala, Sweden (Dnr 2013/459).

\section{Results}

\subsection{Prevalence of Non-Attendance}

Of the 4407 adolescents, the 171 (3.9\%) who reported that they sought dental care only for acute pain or not at all showed non-attendant behavior. Non-attendant 
behavior was reported by $2.1 \%$ of girls and $5.6 \%$ of boys in year $7 ; 2.1 \%$ and $5.4 \%$ of girls and boys, respectively, in year 9, and 3.4\%, and $5.1 \%$ of girls and boys in Grade 2. Non-attendant behavior was more common among boys of all ages (Table 2).

\subsection{Patterns of Associations with Non-Attendant Behavior: Multivariate Analysis}

Component 1, Sociodemographic factors, showed the strongest explanatory value of all components (Nagelkerke's $\mathrm{R}^{2}=0.056$ ), with the variables parental employment status $(\mathrm{OR}=3.10 ; 95 \% \mathrm{CI}: 1.66$ - 5.80), being a boy $(\mathrm{OR}=2.22 ; 95 \%$ $\mathrm{CI}: 1.60$ - 3.08), and foreign-born (OR = 2.14; 95\% CI: $1.38-3.32)$ associated with non-attendance among adolescents (Table 3). Seventy adolescents reported "No knowledge" on the parental employment status question, which may be explained by their living away from their parents (e.g., in foster care, or having moved away from home). The second strongest explanatory component was Component 4, Health behavior (Nagelkerke's $\mathrm{R}^{2}=0.043$ ). The variables having no regular eating habits $(\mathrm{OR}=2.73 ; 95 \% \mathrm{CI}: 1.07$ - 6.96), consuming sweet drinks/ foods every day (OR = 2.04; 95\% CI: 1.45 - 2.88), being overweight $(\mathrm{OR}=$ 1.75; 95\% CI: 1.18 - 2.61), and risky alcoholic habits (OR = 1.62; 95\% CI: 1.03 2.53) were all associated with non-attendant behavior. The same explanation value (Nagelkerke's $\mathrm{R}^{2}=0.029$ ) was associated with Components 2 , 3, and 5, with significant ORs ranging from 1.56 to 3.92 for non-attendant behavior. The independent measures with the strongest association with non-attendant behavior were having poor/ very poor self-rated oral health (OR = 3.92; 95\% CI: 2.28 6.73), and at least one disability (OR = 1.86; 95\% CI: 1.33 - 2.59; Component 2, Self-rated health), experience of injury or accident (OR $=1.74 ; 95 \% \mathrm{CI}: 1.37$ 2.21), been offended/beaten by an adult not in school (OR = 1.62; 95\%CI: 1.13 -

Table 2. Sample characteristics of non-attendant and attendant adolescents in compulsory school Grades 7 and 9 and high school Grade 2 in Örebro County, Sweden (2014).

\begin{tabular}{|c|c|c|c|c|c|c|}
\hline & & \multicolumn{2}{|c|}{ Non-attendant adolescents } & \multicolumn{2}{|c|}{ Attendant adolescents } & \multirow{2}{*}{$\frac{\text { Total }}{\mathrm{n}}$} \\
\hline & & $\mathrm{n}$ & $\%$ & $\mathrm{n}$ & $\%$ & \\
\hline \multicolumn{2}{|c|}{ All subjects } & 171 & 3.9 & 4236 & 96.1 & 4407 \\
\hline \multirow[t]{3}{*}{ School year 7} & Girls & 16 & 2.1 & 762 & 97.9 & 778 \\
\hline & Boys & 42 & 5.6 & 714 & 94.4 & 756 \\
\hline & Total & 58 & 3.8 & 1476 & 96.2 & 1534 \\
\hline \multirow[t]{3}{*}{ School year 9} & Girls & 16 & 2.1 & 735 & 97.9 & 751 \\
\hline & Boys & 34 & 5.4 & 591 & 94.6 & 625 \\
\hline & Total & 50 & 3.6 & 1326 & 96.4 & 1376 \\
\hline \multirow[t]{3}{*}{ Grade 2} & Girls & 25 & 3.4 & 721 & 96.6 & 746 \\
\hline & Boys & 38 & 5.1 & 713 & 94.9 & 751 \\
\hline & Total & 63 & 4.2 & 1434 & 95.8 & 1497 \\
\hline
\end{tabular}


Table 3. Multivariate logistic regression models for non-attendant behavior in adolescents: distribution and number of responses per factor (n), odds ratio (OR) with 95\% confidence intervals $(95 \% \mathrm{CI})$ for the outcome variables within components of risk factors.

\begin{tabular}{|c|c|c|c|c|c|c|}
\hline Component & Variable & $\mathbf{n}$ & OR & $95 \% \mathrm{CI}$ & $P$-value & $\begin{array}{c}\text { Nagelkerke's } \\
\mathbf{R}^{2}\end{array}$ \\
\hline \multirow{17}{*}{$\begin{array}{l}\text { (I) Sociodemographic } \\
\text { factors }\end{array}$} & Gender & & & & & 0.056 \\
\hline & $\operatorname{Girl}(r e f)$ & 2275 & & & & \\
\hline & Boy & 2132 & 2.22 & $1.6-3.08$ & $<0.001$ & \\
\hline & School year & & & & & \\
\hline & School year 7 (ref) & 1534 & & & & \\
\hline & School year 9 & 1376 & 1.0 & $0.68-1.47$ & 0.991 & \\
\hline & High school Grade 2 & 1497 & 1.11 & $0.77-1.6$ & 0.580 & \\
\hline & Country of birth & & & & & \\
\hline & Swedish born, with & & & & & \\
\hline & $\begin{array}{l}\text { Swedish-born parents } \\
(\text { reff })\end{array}$ & 3231 & & & & \\
\hline & $\begin{array}{l}\text { Swedish born, with } \\
\text { foreign-born parents }\end{array}$ & 761 & 1.26 & $0.83-1.9$ & 0.281 & \\
\hline & Foreign born & 415 & 2.14 & $1.38-3.32$ & 0.001 & \\
\hline & Parental occupation & & & & & \\
\hline & $\begin{array}{l}\text { Two parents employed } \\
\text { (ref) }\end{array}$ & 3305 & & & & \\
\hline & One parent employed & 901 & 1.74 & $1.21-2.51$ & 0.003 & \\
\hline & No parent employed & 131 & 3.10 & $1.66-5.8$ & $<0.001$ & \\
\hline & No knowledge ${ }^{*}$ & 70 & 2.20 & $0.93-5.2$ & 0.074 & \\
\hline \multirow[t]{6}{*}{ (II) Self-rated health } & Disability & & & & & 0.029 \\
\hline & No disabilities (ref) & 3514 & & & & \\
\hline & At least one disability ${ }^{* *}$ & 893 & 1.86 & $1.33-2.59$ & $<0.001$ & \\
\hline & Oral health & & & & & \\
\hline & $\begin{array}{l}\text { Not bad/not very bad } \\
\text { self-rated own oral } \\
\text { health }\end{array}$ & 4279 & & & & \\
\hline & $\begin{array}{l}\mathrm{Bad} / \text { very bad self-rated } \\
\text { own oral health }\end{array}$ & 128 & 3.92 & $2.28-6.73$ & $<0.001$ & \\
\hline \multirow[t]{6}{*}{$\begin{array}{l}\text { (III) Perceived } \\
\text { life-events }\end{array}$} & $\begin{array}{c}\text { Experience of injury or } \\
\text { accident }\end{array}$ & & & & & 0.029 \\
\hline & No $(r e f)$ & 3029 & & & & \\
\hline & Yes & 1378 & 1.74 & $1.37-2.21$ & $<0.001$ & \\
\hline & Been bullied & & & & & \\
\hline & No $(r e f)$ & 3908 & & & & \\
\hline & Yes & 499 & 0.73 & $0.5-1.08$ & 0.113 & \\
\hline
\end{tabular}




\section{Continued}

Being abused/ beaten by

an adult, not in school

$\begin{array}{ccccc}\text { No }(r e f) & 4015 & & & \\ \text { Yes } & 392 & 1.62 & 1.13-2.32 & 0.008\end{array}$

(IV) Health behavior Risky alcoholic habits

No $($ ref $) \quad 4005$

Yes

402

$\begin{array}{lll}1.62 & 1.03-2.53 \quad 0.036\end{array}$

Smoking every day

$\begin{array}{ccccc}\text { No }(\text { ref) } & 4219 & & & \\ \text { Yes } & 188 & 1.26 & 0.69-2.31 & 0.461\end{array}$

Regular eating habits

Yes $($ ref $) \quad 2014$

Neither good nor bad

$\begin{array}{llll}2346 & 1.13 & 0.81-1.57 & 0.471\end{array}$

Irregular eating habits

$\begin{array}{llll}47 & 2.73 & 1.07-6.96 & 0.035\end{array}$

Consumes sweet

drinks/ foods everyday

$\begin{array}{cccccc}\text { No }(r e f) & 3602 & & & \\ \text { Yes } & 805 & 2.04 & 1.45-2.88 & <0.001\end{array}$

Body mass index

$\begin{array}{ccccc}\text { Normal (ref) } & 3717 & & & \\ \text { Overweight } & 556 & 1.75 & 1.18-2.61 & 0.006 \\ \text { Obese } & 134 & 1.22 & 0.55-2.7 & 0.631\end{array}$

(V) Social cohesion and social capital

Trusts parents

$\begin{array}{ccccc}\text { Yes (ref) } & 4176 & & & \\ \text { No or insecure } & 231 & 1.74 & 1.16-2.6 & 0.046 \\ \begin{array}{c}\text { Has someone to share } \\ \text { innermost feelings with }\end{array} & & & & \\ \text { Yes (ref) } & 2780 & & & \\ \text { No } & 1627 & 1.62 & 1.24-2.1 & 0.006 \\ \begin{array}{c}\text { Has close friends } \\ \text { atschool }\end{array} & & & & \\ \text { Yes (ref) } & 4035 & & & \\ \text { No } & 372 & 1.70 & 1.19-2.43 & 0.008\end{array}$

Likes being at school

$\begin{array}{ccccc}\text { Yes (ref) } & 3663 & & & \\ \text { No } & 744 & 1.56 & 1.15-2.12 & 0.039\end{array}$

${ }^{*}$ No knowledge means that they do not know because they have been placed in foster care or for other reasons do not live with their parents; ${ }^{*}$ The county council of Örebro have national intake data for deaf and blind schoolchildren 
2.32; Component3, Perceived lifeevents), and no one to share [their] innermost feelings with (OR = 1.74; 95\% CI: 1.16 - 2.60) and no close friends at school (OR $=1.70$; 95\% CI: $1.19-2.43$; Component 5 , Social cohesion and social capital).

\subsection{Suggested Model for Factors Associated with Non-Attendance}

Based on these findings, we suggest a model for factors associated with non-attendant behavior in adolescents (Figure 3). In this model, the Nagelkerke explanatory values for each component decided the relation to the outcome by size and placement; in each component, we included the variables with the strongest ORs.

Almost all studied variables had a statistically significant association with non-attendant behavior in adolescents (Table 3); however, there were differences in the strength of these associations, with significant ORs ranging from 1.56 to 3.92 (Figure 3).

\section{Discussion}

This study is the first to assess the prevalence of self-rated non-attendant behavior among adolescents and its association with their lives and health outside the clinical setting. A strong association was found between non-attendant behavior

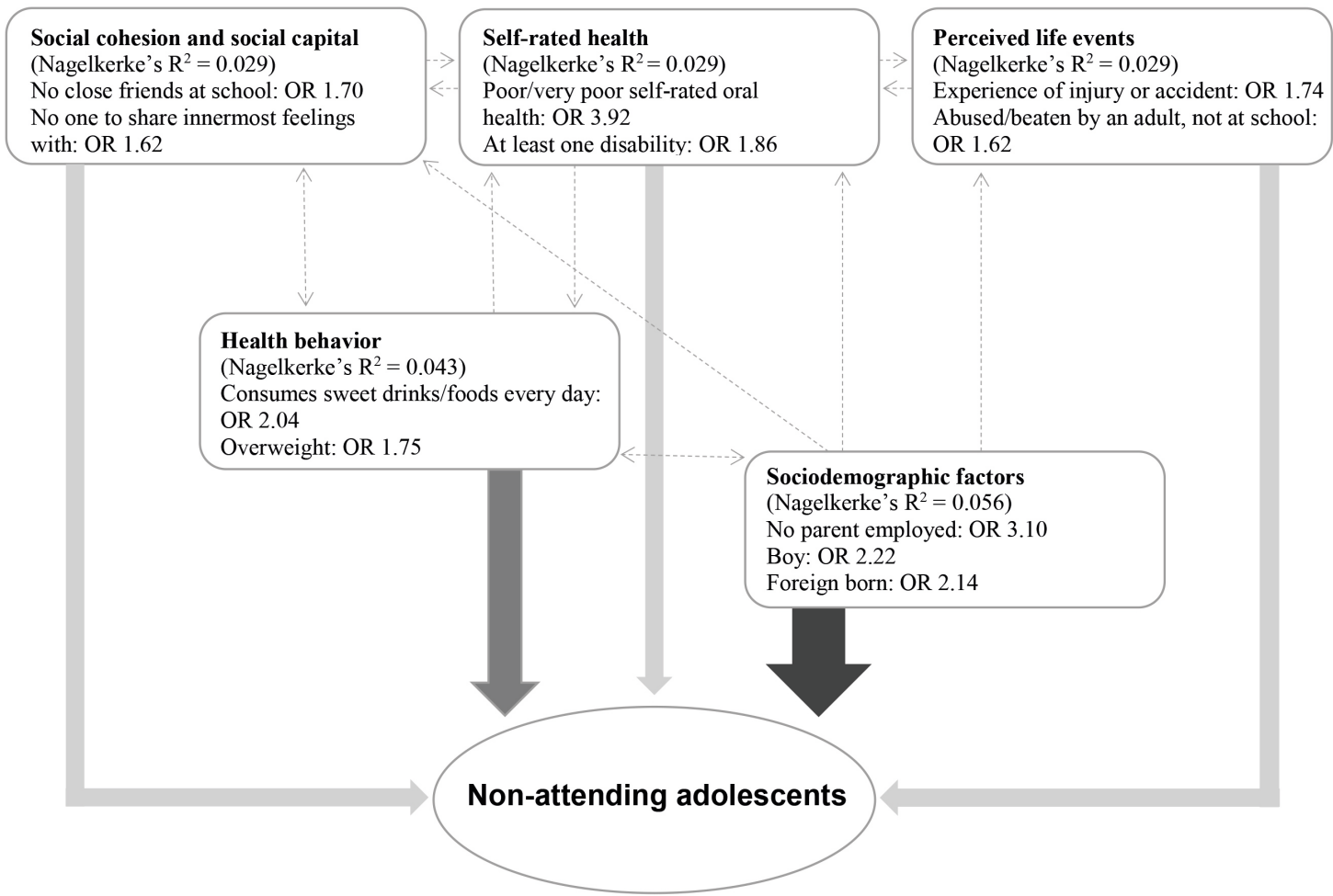

Figure 3. Suggested model for risk factors for non-attending among adolescents based on study findings, where filled arrows show associations between the five different components and non-attendant adolescents and dotted arrows show the hypothetical link between the different components. The different shades of grey indicate the strength of the association where the strongest R2 is denoted with the darkest grey shade and decreasing R2 with decreasing shades. 
and sociodemographic factors such as being a boy, being born outside Sweden, and living with parents who are not in the labor market. Health behaviors, such as consuming sweet drinks/foods every day and being overweight were also associated with non-attendant behavior.

In this study, we choose to include only adolescents who answered all the questions in the questionnaire, resulting in a response rate of $60 \%$ (4407/7399). Significant results will be discussed in terms of the conceptual model shown in Figure 2.

\subsection{Individual Factors: Sociodemographic Factors}

Being a boy, being foreign-born, and having parents outside the labor market were associated with non-attending behavior, in line with previous findings (Okullo et al., 2004; Ostberg et al., 2010; Skaret et al., 2007; Skaret et al., 1998, 2000). Those individual factors are also associated with dental caries (Julihn, Barr Agholme, Grindefjord, \& Modeer, 2006; Kallestal \& Fjelddahl, 2007) and risk for exposure to critical life events (Annerback, Wingren, Svedin, \& Gustafsson, 2010) and to poor oral health (Ostberg, Lindblad, \& Halling, 2003). We found no difference by age, which may be explained by our inclusion of adolescents only.

\subsection{Self-Rated Health}

Three percent of our sample reported poor or very poor oral health (128 adolescents), which was associated with non-attendance and almost all who reported poor or very poor oral health rated themselves as attending scheduled dental care. Poor oral health has been shown to coincide with inferior overall health, disabilities (Blomqvist et al., 2006; Carlsson et al., 2013), and non-attendant behavior \{Vingilis, 2007 \#1280; Wigen, 2009 \#446; Lopez, 2007 \#1274\}. Twenty percent (893 adolescents) had at least one disability, quite a high portion that may be explained by the county council of Örebro's national intake of deaf and blind schoolchildren. This finding of an association between disability and non-attending behavior is new and raises questions about the content and efficiency of the "call system" and the availability of dental care, which may not be suitable for adolescents with special needs.

\subsection{Perceived Life Events}

It was significantly more common among non-attendants to have been exposed to any form of critical life events. Kvist et al. (2013), found that adolescents who rated their oral health as poor had significantly more often been exposed to any kind of abuse, which coincides with our results. We found also that those who had been subjected to sexual abuse assessed themselves as attending regular dental care (data not shown). However, sexual abuse has been associated with dental anxiety and dental fear (Willumsen, 2001) and child abuse with poor oral health (Kvist et al., 2013), but research into the influence of critical life events on attendance to dental care is scarce. 


\subsection{Health Behavior}

Consuming sweet drinks/foods every day is not good for overall or oral health and the associated health risks (NCD Risk Factor Collaboration (NCD-RisC), 2017) are well-known, but we also found it to be associated with non-attendant behavior. Being overweight or obese has been shown to be linked to physical inactivity (An, 2017), caries (Costacurta et al., 2011), and poor oral health (Khan, Barrington, Bettiol, Barnett, \& Crocombe, 2018) primarily because of the increased consumption of unhealthy food and physical inactivity (NCD Risk Factor Collaboration (NCD-RisC), 2017; Neovius, 2011). Unhealthy weight increased in recent years among Swedish children and adolescents, but has lately fallen back to previous levels (NCD Risk Factor Collaboration (NCD-RisC), 2017; Neovius, 2011).

\subsection{Social Cohesion and Social Capital}

Disadvantaged social situations have been linked to disease through psychosocial and behavioral pathways. Even a subtle social disturbances such as loneliness can lead directly to poor health behavior (Burt, 2005). In our group of adolescents, we found an association between non-attending behavior and having no one to confide in and no close friends at school.

\subsection{Suggested Model for Risk Factors}

Almost $4 \%$ of our sample rated themselves as not attending dental care ("I only go when it is absolutely necessary, as in emergency situations, or when I have a toothache' or 'I completely avoid dental care'"). This is a small proportion, but should not be neglected, considering that all children in Sweden are offered regular individual dental care, free of charge, to the age of 22 years.

Our conceptual model was created using previously known factors for non-attendance to guide the analysis. We found several factors associated with non-attendance and our analysis strengthens previously identified associations. We therefore suggest a risk factor model for non-attending behavior to clarify the complexity of non-attending behavior. Several of the factors and how they influence each other is described in the literature and well-known, but we do not know how they interact to affect non-attendance in adolescents. These relationships must be further evaluated for us to better the understand risks for non-attendant behavior in adolescents. Deeper knowledge and understanding of non-attending adolescents will help dental personnel to provide adolescents with dental care according to their individual needs and thereby act for the prevention of a non-attending behavior in adulthood.

\subsection{Strengths and Weaknesses}

The study's strengths are its large sample size, the comprehensiveness of the questionnaire, and the survey's presentation during school hours, which increased the number of adolescents who were reached over those approached in 
clinical studies. However, the choice to include only questionnaires with no internal loss reduced the sample substantially and could possibly have introduced a bias. We gathered information from non-attendant adolescents directly, but by their own self-assessed behavior rather than through dental records. The non-attending group was small, leading to statistical analytical problems with managing data for rare behaviors. Multicollinearity due to the correlations between some independent variables may have limited our ability to detect some statistically significant associations. We tried to limit the number of variables by selecting one of two to three variables to measure the one specific behavior. There might also be residual confounding from important factors not being captured by the questionnaire. Because the survey was conducted cross-sectionally, no causality can be reasonably attributed; however, we believe that the study design allows us to define associations between non-attending behavior in adolescents and many sociodemographic and psychosocial factors. The county of Örebro is considered to represent Sweden well, both sociodemographically and in terms of caries among adolescents (Socialstyrelsen, 2015b). This new model, based on the analysis of a sample of Swedish adolescents, must be tested for external validity in other populations since parts of non-attending behavior could be context-dependent.

\section{Conclusion}

This study shows a strong association between non-attendant behavior and sociodemographic factors and health behavior. It also adds knowledge of the increased vulnerability to non-attendance associated with adolescents having at least one disability and/or experience of critical life.

\section{Future Research}

Future studies to validate the suggested model for risk factors with data from another sample would be helpful for gaining a deeper understanding of non-attending behavior in adolescents, which could be used to support their general health. With more knowledge about risk factors for non-attendance it should be possible to adapt care to promote the oral health of young people and to contribute to their continuous dental care through adulthood.

\section{Acknowledgements}

Not applicable.

\section{Funding}

This study was supported by grants from Public Dental Service, Region Örebro County, Sweden.

\section{Availability of Data and Materials}

All Swedish "Life \& Health: Youth" 2014 data is accessible upon reasonable re- 
quest from the Department for Sustainable Development, Region Örebro County, Sweden.

\section{Authors' Contributions}

All authors contributed to the design of this study. Analyses were performed by AG and CP, and all authors contributed to the interpretation of data. All authors contributed to writing the manuscript and approved the final version.

\section{Authors' Information}

Department of Pedodontics, Postgraduate Dental Education Center, Örebro County Council, Box 1126, SE 70111 Örebro, Sweden.

\section{Ethics Approval and Consent to Participate}

The "Life \& Health: Youth" survey is carried out every third year and follows the ethical principles of the WMA Helsinki declarations in protecting integrity, privacy and confidentiality of participants. This study was approved by the regional Ethical Review Board of Uppsala, Sweden (Dnr 2013/459). Participation in the "Life \& Health: Youth" is voluntary and anonymous, and all participants are informed about the objectives of the survey.

\section{Consent for Publication}

Not applicable.

\section{Conflicts of Interest}

The authors have no competing interests to declare.

\section{References}

An, R. (2017). Diet Quality and Physical Activity in Relation to Childhood Obesity. International Journal of Adolescent Medicine and Health, 29. https://doi.org/10.1515/ijamh-2015-0045

Andrews, R., Morgan, J. D., Addy, D. P., \& McNeish, A. S. (1990). Understanding Non-Attendance in Outpatient Paediatric Clinics. Archives of Disease in Childhood, 65, 192-195. https://doi.org/10.1136/adc.65.2.192

Annerback, E. M., Wingren, G., Svedin, C. G., \& Gustafsson, P. A. (2010). Prevalence and Characteristics of Child Physical Abuse in Sweden: Findings from a Population-Based Youth Survey. Acta Paediatrica, 99, 1229-1236. https://doi.org/10.1111/j.1651-2227.2010.01792.x

Appleton, J., Powell, C., \& Coombes, L. (2016). Children's Missed Healthcare Appointments: Professional and Organisational Responses. Archives of Disease in Childhood, 101, 814-818. https://doi.org/10.1136/archdischild-2015-309621

Blomqvist, M., Holmberg, K., Fernell, E., Ek, U., \& Dahllof, G. (2006). Oral Health, Dental Anxiety, and Behavior Management Problems in Children with Attention Deficit Hyperactivity Disorder. European Journal of Oral Sciences, 114, 385-390. https://doi.org/10.1111/j.1600-0722.2006.00393.x 
Bowman, R. J., Bennett, H. G., Houston, C. A., Aitchison, T. C., \& Dutton, G. N. (1996). Waiting Times for and Attendance at Paediatric Ophthalmology Outpatient Appointments. BMJ, 313, 1244. https://doi.org/10.1136/bmj.313.7067.1244

Brogardh-Roth, S., Mansson, J., Ridell, K., Alward, L., Hellen-Halme, K., \& Ekberg, E. (2017). Five Years' Follow-Up of Dental Fear And Anxiety, Experience of Dental Care and Oral Health Behaviour in Swedish Preterm and Full-Term Adolescents. BMC Oral Health, 17, 145. https://doi.org/10.1186/s12903-017-0431-0

Brown, G. W., \& Harris, T. (1978). Social Origins of Depression: A Reply. Psychological Medicine, 8, 577-588. https://doi.org/10.1017/S0033291700018791

Burt, B. A. (2005). Concepts of Risk in Dental Public Health. Community Dentistry and Oral Epidemiology, 33, 240-247. https://doi.org/10.1111/j.1600-0528.2005.00231.x

Cameron, E., Heath, G., Redwood, S., Greenfield, S., Cummins, C., Kelly, D., \& Pattison, H. (2014). Health Care Professionals' Views of Paediatric Outpatient Non-Attendance: Implications for General Practice. Family Practice, 31, 111-117. https://doi.org/10.1093/fampra/cmt063

Carlsson, V., Hakeberg, M., Blomkvist, K., \& Wide Boman, U. (2013). Attention Deficit Hyperactivity Disorder and Dental Anxiety in Adults: Relationship with Oral Health. European Journal of Oral Sciences, 121, 258-263. https://doi.org/10.1111/eos.12016

Carpiano, R. M. (2007). Neighborhood Social Capital and Adult Health: An Empirical Test of a Bourdieu-Based Model. Health \& Place, 13, 639-655.

https://doi.org/10.1016/j.healthplace.2006.09.001

Chariatte, V., Berchtold, A., Akre, C., Michaud, P. A., \& Suris, J. C. (2008). Missed Appointments in an Outpatient Clinic for Adolescents, an Approach to Predict the Risk of Missing. Journal of Adolescent Health, 43, 38-45.

https://doi.org/10.1016/j.jadohealth.2007.12.017

Cooper, N. A., \& Lynch, M. A. (1979). Lost to Follow Up: A Study of Nonattendance at a General Paediatric Outpatient Clinic. Archives of Disease in Childhood, 54, 765-769. https://doi.org/10.1136/adc.54.10.765

Costacurta, M., Di Renzo, L., Bianchi, A., Fabiocchi, F., De Lorenzo, A., \& Docimo, R. (2011). Obesity and Dental Caries in Paediatric Patients. A Cross-Sectional Study. European Journal of Paediatric Dentistry, 12, 112-116.

Davoglio, R. S., Abegg, C., \& Aerts, D. R. (2013). Factors Related to the Use of Dental Services among Adolescents from Gravatai, RS, Brazil, in 2005. Revista Brasileira de Epidemiologia, 16, 546-554. https://doi.org/10.1590/S1415-790X2013000200028

Denton, M., Prus, S., \& Walters, V. (2004). Gender Differences in Health: A Canadian Study of the Psychosocial, Structural and Behavioural Determinants of Health. Social Science and Medicine, 58, 2585-2600. https://doi.org/10.1016/j.socscimed.2003.09.008

Freire, M. C., Sheiham, A., \& Hardy, R. (2001). Adolescents' Sense of Coherence, Oral Health Status, and Oral Health-Related Behaviours. Community Dentistry and Oral Epidemiology, 29, 204-212. https://doi.org/10.1034/j.1600-0528.2001.290306.x

Giunta, D., Briatore, A., Baum, A., Luna, D., Waisman, G., \& de Quiros, F. G. (2013). Factors Associated with Nonattendance at Clinical Medicine Scheduled Outpatient Appointments in a University General Hospital. Patient Prefer Adherence, 7, 1163-1170.

Gustafsson, A., Arnrup, K., Broberg, A. G., Bodin, L., \& Berggren, U. (2007). Psychosocial Concomitants to Dental Fear and Behaviour Management Problems. International Journal of Paediatric Dentistry, 17, 449-459. https://doi.org/10.1111/j.1365-263X.2007.00883.x

Gustafsson, A., Broberg, A. G., Bodin, L., Berggren, U., \& Arnrup, K. (2010). Possible 
Predictors of Discontinuation of Specialized Dental Treatment among Children and Adolescents with Dental Behaviour Management Problems. European Journal of Oral Sciences, 118, 270-277. https://doi.org/10.1111/j.1600-0722.2010.00734.x

Hallberg, U., Camling, E., Zickert, I., Robertson, A., \& Berggren, U. (2008). Dental Appointment No-Shows: Why Do Some Parents Fail to Take Their Children to the Dentist? International Journal of Paediatric Dentistry, 18, 27-34.

Haugejorden, O., Klock, K. S., Astrom, A. N., Skaret, E., \& Trovik, T. A. (2008). Socio-Economic Inequality in the Self-Reported Number of Natural Teeth among Norwegian Adults-An Analytical Study. Community Dentistry and Oral Epidemiology, 36, 269-278. https://doi.org/10.1111/j.1600-0528.2007.00367.x

Julihn, A., Barr Agholme, M., Grindefjord, M., \& Modeer, T. (2006). Risk Factors and Risk Indicators Associated with High Caries Experience in Swedish 19-Year-Olds. Acta Odontologica Scandinavica, 64, 267-273. https://doi.org/10.1080/00016350600613534

Kallestal, C., \& Fjelddahl, A. (2007). A Four-Year Cohort Study of Caries and Its Risk Factors in Adolescents with High and Low Risk at Baseline. Swedish Dental Journal, 31, 11-25.

Khan, S., Barrington, G., Bettiol, S., Barnett, T., \& Crocombe, L. (2018). Is Overweight/Obesity a Risk Factor for Periodontitis in Young Adults and Adolescents? A Systematic Review. Obesity Reviews, 19, 852-883. https://doi.org/10.1111/obr.12668

Kheirkhah, P., Feng, Q., Travis, L. M., Tavakoli-Tabasi, S., \& Sharafkhaneh, A. (2016). Prevalence, Predictors and Economic Consequences of No-Shows. BMC Health Services Research, 16, 13. https://doi.org/10.1186/s12913-015-1243-Z

Kvist, T., Annerback, E. M., Sahlqvist, L., Flodmark, O., \& Dahllof, G. (2013). Association between Adolescents' Self-Perceived Oral Health and Self-Reported Experiences of Abuse. European Journal of Oral Sciences, 121, 594-599. https://doi.org/10.1111/eos.12084

Lopez, R. (2007). Social Inequalities May Lead to Higher Caries Experience among Indigenous Children in the Northern Territory of Australia. Journal of Evidence-Based Dental Practice, 7, 136-137. https://doi.org/10.1016/j.jebdp.2007.05.009

Lopez, R., \& Baelum, V. (2007). Factors Associated with Dental Attendance among Adolescents in Santiago, Chile. BMC Oral Health, 7, 4.

https://doi.org/10.1186/1472-6831-7-4

Lu, H. X., Wong, M. C., Lo, E. C., \& McGrath, C. (2011). Trends in Oral Health from Childhood to Early Adulthood: A Life Course Approach. Community Dentistry and Oral Epidemiology, 39, 352-360. https://doi.org/10.1111/j.1600-0528.2011.00611.x

McClure, R. J., Newell, S. J., \& Edwards, S. (1996). Patient Characteristics Affecting Attendance at General Outpatient Clinics. Archives of Disease in Childhood, 74, 121-125. https://doi.org/10.1136/adc.74.2.121

NCD Risk Factor Collaboration (NCD-RisC) (2017). Worldwide Trends in Body-Mass Index, Underweight, Overweight, and Obesity from 1975 to 2016: A Pooled Analysis of 2416 Population-Based Measurement Studies in 128.9 Million Children, Adolescents, and Adults. The Lancet, 390, 2627-2642.

https://doi.org/10.1016/S0140-6736(17)32129-3

Neal, R. D., Hussain-Gambles, M., Allgar, V. L., Lawlor, D. A., \& Dempsey, O. (2005). Reasons for and Consequences of Missed Appointments in General Practice in the UK: Questionnaire Survey and Prospective Review of Medical Records. BMC Family Practice, 6, 47. https://doi.org/10.1186/1471-2296-6-47

Neal, R. D., Lawlor, D. A., Allgar, V., Colledge, M., Ali, S., Hassey, A., Wilson, A. et al. 
(2001). Missed Appointments in General Practice: Retrospective Data Analysis from Four Practices. British Journal of General Practice, 51, 830-832.

Neovius, M., \& Rasmussen, F. (2011). Alarmerande Siffror för övervikt och fetma i Sverige och världen. Lakartidningen, 108, 2566-2568.

Okullo, I., Astrom, A. N., \& Haugejorden, O. (2004). Social Inequalities in Oral Health and in Use of Oral Health Care Services among Adolescents in Uganda. International Journal of Paediatric Dentistry, 14, 326-335. https://doi.org/10.1111/j.1365-263X.2004.00568.x

Ostberg, A. L., Ericsson, J. S., Wennstrom, J. L., \& Abrahamsson, K. H. (2010). Socio-Economic and Lifestyle Factors in Relation to Priority of Dental Care in a Swedish Adolescent Population. Swedish Dental Journal, 34, 87-94.

Ostberg, A. L., Lindblad, U., \& Halling, A. (2003). Self-Perceived Oral Health in Adolescents Associated with Family Characteristics and Parental Employment Status. Community Dent Health, 20, 159-164.

Pais, M. S., \& Bissell, S. (2006). Overview and Implementation of the UN Convention on the Rights of the Child. The Lancet, 367, 689-690.

https://doi.org/10.1016/S0140-6736(06)68267-6

Ridell, K., Matsson, L., \& Mejare, I. (2007). Background Factors Associated with Endodontic Treatment Due to Caries in Young Permanent Teeth. Acta Odontologica Scandinavica, 65, 219-223. https://doi.org/10.1080/00016350701364904

Roe, M. F., Appleton, J. V., \& Powell, C. (2015). Why Was This Child Not Brought? Archives of Disease in Childhood, 100, 511-512.

https://doi.org/10.1136/archdischild-2014-307856

Skaret, E., Berg, E., Kvale, G., \& Raadal, M. (2007). Psychological Characteristics of Norwegian Adolescents Reporting No Likelihood of Visiting a Dentist in a Situation with Toothache. International Journal of Paediatric Dentistry, 17, 430-438.

https://doi.org/10.1111/j.1365-263X.2007.00869.x

Skaret, E., Raadal, M., Berg, E., \& Kvale, G. (1999). Dental Anxiety and Dental Avoidance among 12 to 18 Year Olds in Norway. European Journal of Oral Sciences, 107, 422-428. https://doi.org/10.1046/j.0909-8836.1999.eos107602.x

Skaret, E., Raadal, M., Kvale, G., \& Berg, E. (1998). Missed and Cancelled Appointments among 12-18-Year-Olds in the Norwegian Public Dental Service. European Journal of Oral Sciences, 106, 1006-1012. https://doi.org/10.1046/j.0909-8836.1998.eos106605.x

Skaret, E., Raadal, M., Kvale, G., \& Berg, E. (2000). Factors Related to Missed and Cancelled Dental Appointments among Adolescents in Norway. European Journal of Oral Sciences, 108, 175-183. https://doi.org/10.1034/j.1600-0722.2000.108003175.x

Skaret, E., Raadal, M., Kvale, G., \& Berg, E. (2003). Gender-Based Differences in Factors Related to Non-Utilization of Dental Care in Young Norwegians. A Longitudinal Study. European Journal of Oral Sciences, 111, 377-382. https://doi.org/10.1034/j.1600-0722.2003.00072.x

Socialstyrelsen (2015a). County Council for Dental Care.

Socialstyrelsen (2015b). Karies Bland Barn och ungdomar-Epidemiologiska uppgifter för år 2014. (In Swedish) http://www.socialstyrelsen.se

Thomas, D. (2004). Postal Reminders Can Improve Attendance at Orthodontic Clinics. Evidence-Based Dentistry, 5, 14. https://doi.org/10.1038/sj.ebd.6400244

Vingilis, E., Wade, T., \& Seeley, J. (2007). Predictors of Adolescent Health Care Utilization. Journal of Adolescence, 30, 773-800.

https://doi.org/10.1016/j.adolescence.2006.10.001 
Waller, J., \& Hodgkin, P. (2000). Defaulters in General Practice: Who Are They and What Can Be Done about Them? 2 Family Practice, 17, 252-253.

https://doi.org/10.1093/fampra/17.3.252

Willumsen, T. (2001). Dental Fear in Sexually Abused Women. European Journal of Oral Sciences, 109, 291-296. https://doi.org/10.1034/j.1600-0722.2001.00069.x

Wogelius, P., Poulsen, S., \& Sorensen, H. T. (2003). Prevalence of Dental Anxiety and Behavior Management Problems among Six to Eight Years Old Danish Children. Acta Odontologica Scandinavica, 61, 178-183. https://doi.org/10.1080/00016350310003468

Yu, S. M., Bellamy, H. A., Schwalberg, R. H., \& Drum, M. A. (2001). Factors Associated with Use of Preventive Dental and Health Services among U.S. Adolescents. Journal of Adolescent Health, 29, 395-405. https://doi.org/10.1016/S1054-139X(01)00252-X

Zimmer-Gembeck, M. J., Alexander, T., \& Nystrom, R. J. (1997). Adolescents Report Their Need for and Use of Health Care Services. Journal of Adolescent Health, 21, 388-399. https://doi.org/10.1016/S1054-139X(97)00167-5

\section{Abbreviations}

DBMP: Dental Behavior Management Problems;

BMI: Body Mass Index;

SPSS: Statistical package for social sciences. 